\title{
Critical Factors for Food Safety in Global Commodity Flows with a Focus on Logistics - A Case Study on Mycotoxin Contamination of Agri-Bulk Commodities
}

\author{
Milena Alexandra Zupaniec \\ German Federal Institute for Risk Assessment, \\ Max-Dohrn-Str. 8-10, 10589 Berlin, Germany \\ Email: milena.zupaniec@posteo.de (Corresponding Author)
}

Helmut-A. Schafft

German Federal Institute for Risk Assessment, Max-Dohrn-Str. 8-10, 10589 Berlin, Germany Email: helmut.schafft@bfr.bund.de

Ann-Kathrin Lindemann

German Federal Institute for Risk Assessment, Max-Dohrn-Str. 8-10, 10589 Berlin, Germany Email: ann-kathrin.lindemann@bfr.bund.de

\author{
Robert Pieper \\ German Federal Institute for Risk Assessment, \\ Max-Dohrn-Str. 8-10, 10589 Berlin, Germany \\ Email: robert.pieper@bfr.bund.de
}

Anneluise Mader

German Federal Institute for Risk Assessment, Max-Dohrn-Str. 8-10, 10589 Berlin, Germany

Email: anneluise.mader@bfr.bund.de

\begin{abstract}
Logistics as the link between the different stages of the food supply chain can, due to its complexity, provide multiple opportunities for food / feed contamination along global commodity flows. Considering comprehensive international food safety regulations, such as the Regulation (EU) 2019/1381, risk assessment in the field of consumer health protection requires specific approaches determining the impact of logistics on food safety. To identify critical dimensions and corresponding critical factors for food safety in global commodity flows and map complex interactions, we conducted a case study on mycotoxin contamination of agricultural commodities. Accordingly, we interviewed 24 stakeholders directly or indirectly involved in the European and global purchasing and logistics sector of agricultural commodities. Based on the outcome of the interviews, the most relevant dimensions are Logistical processes, Food safety measures, Human factor, Disruptions and shifts, Logistics related conditions, Cooperation, Main Characteristics of the procurement sector and Port characteristics. Food safety risks along global commodity flows are not solely attributable to the
\end{abstract}

logistics sector per se. In particular, Food safety measures (e.g. Quality management and Sampling) that are not adapted to the logistics sector, as well as varying Logistics related conditions (e.g. Infrastructure and Standards) have proven to be major food safety challenges. By providing an overall picture of global commodity flows, the study contributes to reduce current uncertainties in risk assessment. The identified food safety challenges in the logistics sector need to be addressed holistically throughout the entire supply chain and in cooperation with food safety authorities.

Keywords: food supply chain, food safety risks, expert interviews, globalization

\section{INTRODUCTION}

In the age of globalization and increasing trade volumes, food supply chains have become longer and more complex than ever before, with drastic consequences for food safety. With the multitude and high number of actors, processes, locations and corresponding conditions, global supply chains provide more favourable opportunities for 
contamination of food and feed (van Asselt et al., 2010). Various severe food safety incidents that have occurred on an international scale in recent decades (e.g. mad cow disease, dioxin, salmonella, E. coli) have demonstrated that contaminated food can spread faster and affect large regions. This has dramatically increased general awareness of food safety (Alemanno, 2015). In this way, globalization has made food safety a key public health issue and has confronted the international governance of food safety with the issue of how to manage and assess food safety risks. In particular, investigations or clarification of food safety issues that have already occurred, such as E. coli in 2011, have proven challenging due to the complex interplay of many variables both outside and inside global food supply chains (Buchholz et al., 2011). The knowledge gaps and uncertainties uncovered in the process lead to the consequence that health risk assessment to date is often based on incomplete information or poor data availability.

One area where a particularly large number of knowledge gaps have emerged in the context of uncertainty analyses, are the global commodity flows of food and feed and especially the global logistics sector. Consequently, to date the field of logistics is often missing in risk assessment and the question arises as to what role the logistics sector has played in past food safety events. The lack of information and data in this regard is generally reflected in the fact that in the last decades food safety improvements efforts have focused mainly on the food supply chain stages production, processing and retail - while less attention has been paid to the physical flow of goods connecting these stages (Ryan, 2017). However, it can be assumed that the complexity resulting from the high amount of the intervening and interdependent aspects of global logistics (such as involved actors, processes and logistics related conditions) contribute to a greater extent to the general complexity of global food supply chains and consequently may have an adverse effect on food safety.

Hence, the investigation of global commodity flows in terms of food safety requires a more holistic and differentiated approach. The knowledge about the Hazard Analysis Critical Control Point (HACCP) of logistics processes, which are well defined in food safety standards and guidelines in the context of quality management and which are already enough discussed in literature, is no longer sufficient. Against the background of its outstanding role throughout global food and feed supply chains, its increasing importance with rising global trade and in view of the current knowledge gaps, global commodity flows with the focus on the logistics sector has been identified as a new research field in food safety with the aim of being integrated as an important area of consideration in risk analysis.

Due to a lack of studies, this new research field requires an explorative and pro-active approach that verifies and complements current conceptual knowledge with practical experience from different stakeholders of global commodity flows. Therefore, the goal of the present study is to analyse global logistics from a food safety perspective with the help of a conceptual framework for the identification of food safety risks in global commodity flows (Zupaniec et al., 2020). The following research questions will be used to empirically investigate how the complexity of global commodity flows affects food safety:
- What are the most important critical dimensions for food safety in global commodity flows and how do they interrelate?

- What are potential challenges / weaknesses / difficulties defined as critical factors for food safety within the critical dimensions?

- Which of the identified critical dimensions and critical factors prove to be particularly important for food safety?

To answer these questions, we conducted a case study on mycotoxin contamination in agri-bulk commodity flows by interviewing actors/experts directly and indirectly involved in the international logistics or procurement sector of agri-bulk commodities. This way, we aim to draw plausible conclusions about the impact of global commodity flows on food safety by better understanding complex interrelationships and potential causes of food safety risks. The present work makes a contribution to extend the risk assessment practiced so far by analysing and discussing important risk-relevant aspects from the field of global commodity flows.

\section{LITERATURE REVIEW}

\subsection{Food Safety Measures in Consumer Health Protection}

Against the background of serious food safety incidents, governments and the food industry have been under pressure to develop management, control and enforcement systems at every stage of the supply chain. Since the introduction of the "farm to fork" principle by the European food safety regulation (EC No 178/2002), a variety of public regulations and private sector industry standards have developed over the last 20 years (Webb, 2015). However, outbreaks of food-borne diseases or food safety issues still occur which has made the responsible food safety authorities aware that in times of globalization, risk analysis must undergo a paradigm shift from a "from farm to fork" focus to a more holistic view of food supply chains that requires international cooperation and information sharing (Kruse, 2015).

Within the scope of European and international risk management practices, a variety of systems, approaches and methods have been developed for the identification of emerging food safety risks at an early stage (Marvin et al., 2009). On European Level, these systems are developed by the EFSA, and at the global level, by the FAO and others. These systems are based on the general assumption that beyond the critical points for food safety within the food supply chain, influential sectors, such as technology, environment and regulations, also have an impact on food safety and consequently need to be taken into account in the food monitoring process (Noteborn et al., 2005). The aim of such systems is therefore to identify critical factors or drivers of change within and outside the food supply chain that potentially affect food safety and to continuously monitor relevant indicators in order to identify emerging food safety risks at an early stage. Consequently, data collection is based on a "holistic approach" or "horizon scanning" which includes a number of different qualitative methods and data sources such as literature studies, expert consultations and Delphi studies, but also quantitative methods such as analysis tools and simulation models. 
Risk assessment has therefore recognized the increasing importance of global supply chains and consequently the need to expand or adapt traditional risk assessment towards new approaches and tools. This is also reflected in the new Regulation (EU) 2019/1381, which complements the general EU food law (EU Regulation No. $178 / 2002$ ) with the requirement to increase transparency in the EU risk assessment process. In this context, IT-tools have already been developed in order to better analyse food safety risks along global supply chains (Weiser et al., 2016). However, qualitative methods such as integrative or comprehensive concepts and approaches are also needed to support risk assessment in complex food safety cases. Conventionally, risk assessment has been confined to scientific experts with a relatively low formal input from other interested parties or stakeholders and industry in the form of commission meetings (Wentholt et al., 2009). However, the knowledge gaps and uncertainties that have been uncovered call for a more pro-active system involving multiple stakeholders in assessing and clarifying food safety risks along global food supply chains as already practiced in the early risk identification process.

However, knowledge gaps regarding global commodity flows or logistics were also identified in the area of early risk identification: In case studies of mycotoxin contamination in cereal-based supply chains, logistics as a critical factor was rated relatively high by experts. At the same time, however, it was recognized that due to the poor data situation, further studies are necessary to verify the expert's appraisal (Van der Fels-Klerx et al., 2010).

\subsection{Logistics in the Context of Food Safety}

Most knowledge about food safety risks in logistics exists in various standards and guidelines based on the "farm to fork" approach (e.g. GMP, QS). However, to date, literature lacks data on the impact of complex interrelationships in the logistics sectors within and outside of global commodity flows on food safety. Therefore, a specific conceptual framework based on an extensive literature review was developed in a previous study and is briefly summarized here (Zupaniec et al., 2020).

When considering the logistics sector from a food safety perspective, it is primarily the physical flows of food and feed that are of concern, rather than financial and information flows. In the context of the herewith presented study, global commodity flows are defined as the spatiotemporal transformation of goods through processes such as transportation, up- and unloading. These are carried out by different logistics companies and organized by the procurement and trade sector of the food and feed industry as the customer of logistics processes. The number of parties involved in global commodity flows is continuously increasing between the raw material producer and the compound feed producer and the food industry (Baaken and Lehnen, 2015). It can be assumed that not only the quality management of logistics service providers, but also the cooperation between the logistics company and the customer can play an important role in food safety (Marucheck et al., 2011; Singh and Power, 2009). Furthermore, global commodity flows are subject to different country-specific conditions such as regulations, infrastructure and cultural conditions (Göpfert and Braun, 2013). In the course of globalization, global commodity flows are also exposed to global changes such as market and technology development and finally to global competition, which is characterized by optimization efforts of efficiency and cost reduction (Christopher and Holweg, 2011).

\section{METHODOLOGY}

To investigate the impact of the complexity of global commodity flows on food safety and to identify the critical dimensions and factors and their interrelationships, we decided to use a case study as a research approach. When there is little literature and knowledge about a contemporary phenomenon, new insights can be gained qualitatively and empirically in the form of case studies. Case studies focus on experiential or practical knowledge in the real-life context, i.e. with special consideration of the influence of its social, political and other contexts, whereby the boundaries between phenomenon and context are not always clearly evident (Yin, 2013). Case studies are emphatic in the sense that despite prior planning, the research design evolves as the research process progresses. Case studies often refer to "how" or "why" research questions and to theoretical assumptions.

\subsection{Rationale for Case Study Design}

We decided to investigate the impact of global commodity flows on food safety with the focus on logistics using the example of mycotoxin contamination of agricultural bulk commodities. The import of wheat, maize and soybeans from third countries into the EU takes place largely in the animal feed sector. In the present study, global commodity flows of agri-bulk were narrowed down in our consideration as follows: The focus is on all (logistical) processes after the production of agri-bulk commodities in the third country, up to the buyer (trader or feed industry) in the EU.

Undesirable substances can be transferred from feed into animal products and therefore pose a health risk to the consumer. A well-known case was feed maize contaminated with aflatoxin from Serbia, which led to maximum levels for aflatoxin in raw milk being exceeded in 2013 in other European countries (Kos et al., 2014). Up to $80 \%$ of the notifications within the framework of Quality Managements (QM) standards such as GMP+ can be traced back to agricultural raw materials. Mycotoxins, on the other hand, represent the second main reason for notification after pesticide residues (Hartog, 2017). As mycotoxins are toxic metabolites produced by certain species of mould under favourable environmental conditions (i.e. temperature and humidity) they represent a common health risk. Due to their international importance, occurrence, spread and persistence at all stages of the food supply chain, they are well suited for a holistic investigation of food safety issues along global supply chains (Van der Fels-Klerx et al., 2009). By investigating global commodity flows, special attention is paid to storage mycotoxins such as aflatoxins, which are formed by certain moulds after harvesting during transport and storage and have a "transfer effect" on the animal product. Aflatoxins represent the most frequent reason for entries in the mycotoxins category in the European rapid alert system RASFF (Pigłowski, 2019).

We chose a single case taking the example of mycotoxin contamination of agri-bulk commodities. Since 
very little information is available regarding the interacting dimension of global commodity flows, a detailed investigation of only one case seems to be useful. We have chosen a typical rather general situation as a single case so that conclusions can also be drawn about other comparable situations (Staake, 1994).

As already mentioned, theoretical or research guiding assumptions are necessary for conducting case studies as they form the basis for the case study design / logical plan (Yin, 2013). Their main function is therefore to select appropriate methods and to help to structure, focus and narrow down the data collection. Moreover, data analysis is guided by them. The present study is subject to the following research guiding propositions derived from a conceptual framework for the identification of critical factors in global commodity flows (Zupaniec et al., 2020):

- The type and number of logistical processes and actors involved (1)

- The quality management of logistics service providers, as well as the cooperation between the different actors of global commodity flows (2)

- The quality and capacity of (infrastructure) transport routes and nodes (harbours) (3)

- Differences in country-specific logistics-relevant conditions and dynamic changes within global commodity flows (4)

... all have an influence on potential contamination of agri-bulk commodities with mycotoxins.

\subsection{Data Collection}

We chose in-depth expert interviews as data collection technique since it is the most appropriate method to gain a deep understanding and specific insights of interrelations, backgrounds and context. For this purpose, relevant data cannot be obtained from technical operating documents or archives. Data of interest are real, everyday experiences, as well as individual perceptions / perspectives, motivations and convictions of the experts. The interviewed experts have specific knowledge related to the research interest and are part of the field of action.

The expert sampling was done via deductive sampling, i.e. the selection of experts was derived from prior theoretical knowledge (Zupaniec et al., 2020). Consequently, two selection criteria were used in the sampling procedure. Firstly, the interviewed expert should have knowledge and experience in at least one of the following key areas:

- International logistics in the context of global trade of agri-bulk commodities

- Global trade or procurement of agri-bulk commodities by the food/feed industry

- Food safety guidelines and standards in the area of global food and feed commodity flows
The second requirement was that the experts had basic knowledge and experience in the field of food safety or quality management. Contacting the experts was based to a large extent on the "snowball principle", in which the first interview partners from the existing network referred other possible interview partners (Patton, 2014).

We chose the guided interview as the interview format, which was based on a semi-standardised questionnaire with about 10 guiding questions. The guided interview offers a flexible use through the possibility to adapt the sequence of questions to the course of the interview and to ask follow-up (ad-hoc) questions (Loosen, 2016). The questions referred to a large extent to challenges, barriers or potential for improvement in the following focus areas based on the research guiding propositions mentioned above: 1 . Logistical processes (transport and port activities) 2. Quality management of logistics service providers 3. Cooperation between buyer (trader/feed industry) and logistics service provider and 4. Food safety guidelines, standards and controls. With the help of open questions and targeted "why"- questions, the opinions and experiences of the experts were obtained on the one hand, and on the other hand, this type of question served to learn more about the background or causes of food safety risks and thus the context of global commodity flows.

\subsection{Conducting the Interviews}

The experts were first contacted either directly by telephone or by email with a background paper on the study. If accepted, the experts received a consent form, which they signed and handed over on the day of the interview or before. The interviews were recorded with a digital device, transcribed and anonymised (personal names, company names, institutions, location information: country names, city names, river names) afterwards. Further, demographic data and occupational status were surveyed with a short questionnaire, which were also anonymised and summarised for the total sample in Table 1. A total of 18 interviews were conducted with 24 experts, of which 14 were individual interviews and the remaining 4 interviews consisted of conversations with 2-3 experts. All interviews were conducted by the same person from the research team between August 2019 and December 2019 and had an average length of 57 minutes.

The experts were divided into four different groups of actors, which are shown in Figure 1. The chart shows the number of interviews and experts per stakeholder group and from which sector/area of activity they come. Three different questionnaires were developed with overlapping topics but a different focus (Guideline $\mathrm{A}=$ External controls, standards, regulations; $\mathrm{B}=$ Logistical processes, port activities; $\mathrm{C}=$ Cooperation). As trade and logistics are closely linked, representatives of these sectors / actors groups have received the same questionnaire. 
Table 1 Description of the sample of a total of 24 experts from 18 interviews ( $\mathrm{n}=$ number of experts). Of the 18 interviews, 14 were conducted face to face on site, 3 by phone and 1 by Skype.

\begin{tabular}{|c|c|c|c|c|c|c|c|c|c|}
\hline Gender & $n$ & $\begin{array}{c}\text { Age } \\
\text { (years) }\end{array}$ & $\mathrm{n}$ & $\begin{array}{c}\text { Job Experience } \\
\text { (years) }\end{array}$ & $\mathrm{n}$ & Position & $\mathrm{n}$ & Workplace & $\mathrm{n}$ \\
\hline $\begin{array}{c}\text { Female } \\
\text { Male }\end{array}$ & $\begin{array}{c}5 \\
19\end{array}$ & $\begin{array}{c}30-39 \\
40-49 \\
50-60 \\
>60\end{array}$ & $\begin{array}{c}3 \\
8 \\
10 \\
3\end{array}$ & $\begin{array}{c}3-7 \\
7-15 \\
>15\end{array}$ & $\begin{array}{c}1 \\
6 \\
17\end{array}$ & $\begin{array}{l}\text { Secretary General } \\
\text { Policy Officer Legislation } \\
\text { Managing director } \\
\text { Middle Management } \\
\text { Technical Advisor }\end{array}$ & $\begin{array}{l}1 \\
1 \\
8 \\
9 \\
4\end{array}$ & $\begin{array}{l}\text { Germany } \\
\text { Belgium } \\
\text { Netherland } \\
\text { France } \\
\text { Spain } \\
\text { Italy } \\
\text { South Africa }\end{array}$ & $\begin{array}{c}11 \\
4 \\
3 \\
2 \\
2 \\
1 \\
1\end{array}$ \\
\hline
\end{tabular}

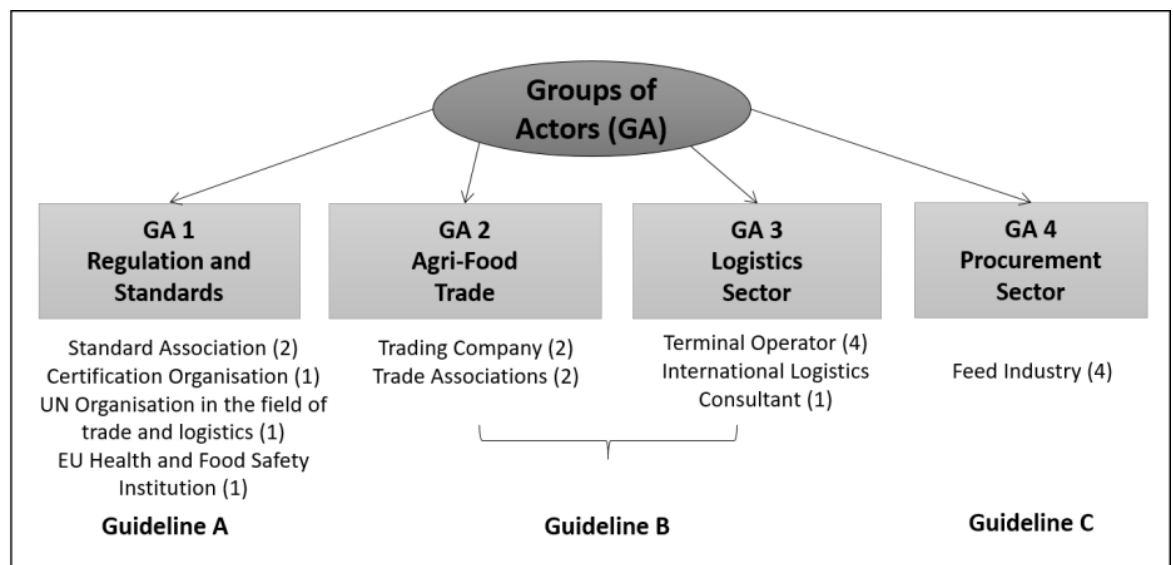

Figure 1 Segregation of the experts into four groups of actors (GA), job affiliation and number of interviews (n)

\subsection{Data Analysis}

The interviews were analysed by one person of the research team by Qualitative content analysis, which involves the coding of the transcribed interviews. Parts of the text are thus ordered according to certain criteria and described by categories (Mayring, 2004). The development of such a category system is aimed at reducing the complexity of the material. The data point in the same direction, i.e. no complete matching or consistency of data is required within a category. For example, parts of the text were coded to the same category if they contained a relevant aspect, which a.) has been explained, b.) has been related to another relevant aspect, c.) has been critically evaluated in the food safety context. The coding unit (the smallest text segment that can be coded) represented a statement / sentence. The formation of categories followed both a deductive and inductive process. This means that the categorisation was based on the above-mentioned theoretical assumptions and at the same time a lot of new information collected through the open questions led to new assumptions and corresponding categories.

The logic used to link the data collected to the propositions or research questions was based on pattern matching. Pattern matching consists of comparing empirically based patterns in the collected data with a predicted pattern or propositions in order to confirm or disprove the assumption and develop additional new assumptions. Further, rival explanations were used as criteria for interpretation. This implies that the systematic search for alternative, plausible explanations / interpretation / views by a different organisation/categorisation of the data determines the way in which knowledge is gained. Both pattern matching and rival explanations strengthens internal validity as important quality criteria for case studies (Yin, 2013).
We used MAXQDA as Computer-Assisted/Aided Qualitative Data Analysis software (CAQDAS) to support category building and data analysis. The transcribed and anonymised interviews and audio files were stored in an interview database. In addition to the raw data, MAXQDA was able to store interview protocols and maintain a continuous research diary ("memo writing"). With the help of MAXQDA, the collected data could be well organised and the entire research process documented, so that the chain of evidence can be traced from the research questions to the present case study report, which increases the reliability of the present study (Yin, 2013).

\section{RESULTS}

Based on the outcome of the expert interviews, eight key dimensions of global commodity flows were found to be the most relevant for mycotoxin contamination / food safety: Logistical processes, Food safety measures, Human factor, Disruptions and shifts, Logistics related conditions, Cooperation, Main characteristics of the procurement sector and Port characteristics. Further, we identified critical factors for mycotoxin contamination / food safety for each dimension. While all identified critical factors are summarised in an overview table (see Appendix 1), the most relevant are addressed in this section.

By using the "Code Co-occurrence Model" in $M A X Q D A$, which records and visualizes the overlapping or common occurrence of codes, the identified key dimensions were put into context. The graphical outcome of the relative impact relationships between the key dimensions is presented in Figure 2. It shows the complex interaction between all identified dimensions, its different relationships (different line thickness) as well as the code frequency for each critical dimension. According to the code frequency, data analysis revealed some critical dimensions and factors 
to be more relevant in the present case study. In the following, the most important dimensions will be addressed by looking closer at the identified factors and related relationships.

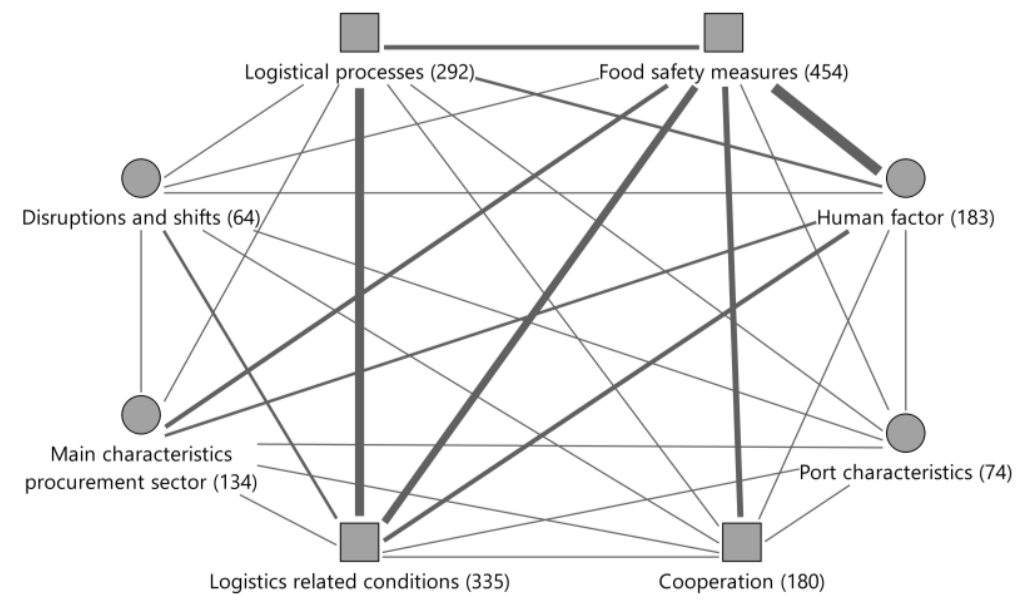

Figure 2 Graphical representation of the relative influence relationships between the identified critical dimensions. Thickness of the lines is proportional to the influence of the dimension considered, e.g., the strong correlation between Human factor and Food safety measures indicates that for example Human factors (e.g., mentality and diligence) have a great impact on the implementation of food safety measures (e.g., QM Management). Frequency of coded segments of each dimension is indicated in the parenthesis (n).

\subsection{Food Safety Measures}

Food safety measures show the most frequent mention of critical factors (Figure 2). This implies that the interviewed experts consider the Food safety measures Quality Management (QM) of Logistics companies, Sampling and Analysis, External Controls and Traceability (see Appendix 1) required by EU food safety policy and applied along global agri-bulk commodity as critical for food safety due to their current weaknesses. Figure 3 shows that among these critical food safety measures, the $Q M$ of Logistics company represents the biggest challenge for ensuring food safety. Although the EU "farm to fork"principle states that logistics companies - as part of the food supply chain - are obliged to carry out their own controls within the scope of a quality management system, the present study revealed that in practice - and especially in a global context - whether a logistics company can establish a QM system depends on a number of factors.

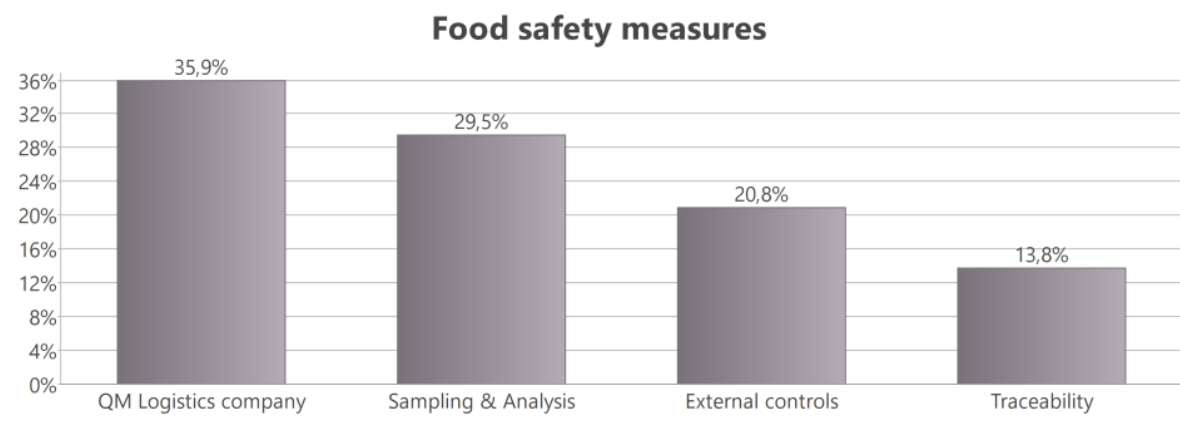

Figure 3 Share of the mention (=coded segments; total code frequency n=454) of sub areas within the dimension "Food Safety Measures" by the interviewed experts.

These factors are to a large extent mutually dependent: whether a QM system is introduced or a trained quality manager or even a quality department is in place depends on the financial and human resources, which are often related to the size of the company and consequently on the degree of internationalisation (see Appendix 1). However, many experts state that the way in which QM is implemented is more important for food safety than whether or not a QM system is in place. Here the human aspect comes into play $(\rightarrow$ Human factor). Figure 4 shows the division of the dimension Human factor into the identified critical factors (see Appendix 1). The number of mentions of the critical factors by the interviewees reflects both their relevance for food safety and their relevance for the different actors involved, such as logistics companies, the feed industry, authorities and inspection bodies. In this context, especially the high mention of Mentality and Diligence (which are mutually dependent) with regard to logistics companies, indicates their respective influence on the quality level of the implemented QM of logistics companies. The lack of integrity of logistics companies can be mainly attributed to the economic pressures and lack of incentives. On the other hand, the lack of knowledge and awareness for food safety as well as experience are rather related to the low attractiveness in the sector due to difficult working conditions and low payment resulting in high labour turnover and relatively lower education level $(\rightarrow$ Main characteristics of procurement sector). 


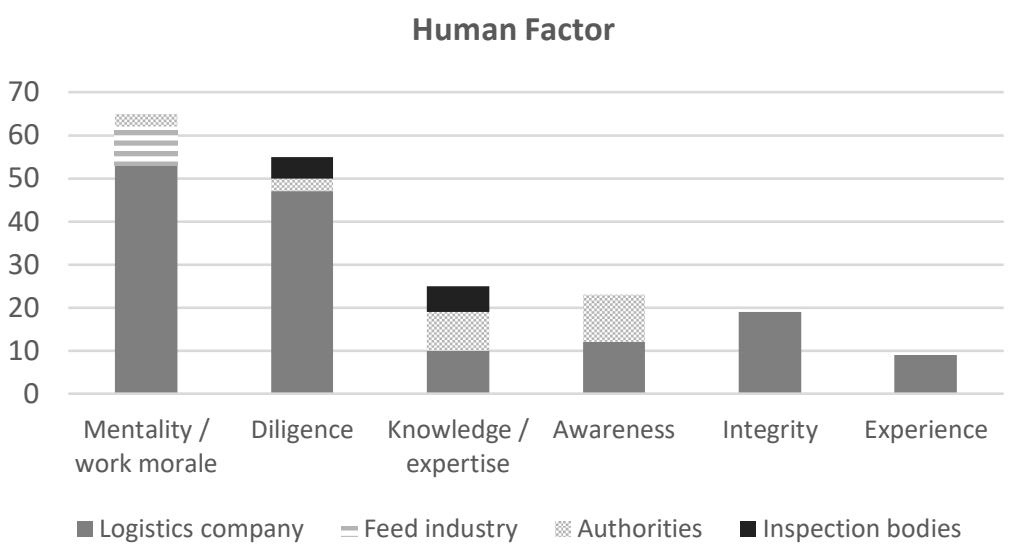

Figure 4 Number of mention (=coded segments; total code frequency n=183) of critical factors in the dimension "Human Factor" by the interviewed experts and respective relevance for different actors.

However, the results show that socio-cultural conditions have a great influence on the human factor, so there are major country-specific differences here ( $\rightarrow$ Logistics related conditions). Furthermore, Figure 3 illustrates that Sampling of agri-bulk commodities during logistical processes and the Analysis of samples assigned by the owner or buyer of the goods (here: trader or feed industry) represent the next major challenge for ensuring food safety along global commodity flows according to the experts (see Appendix 1). At first the sampling frequency of a trading unit has to be considered critically as it determines to a large extent whether and how much contamination is found. The sampling plan is based on a risk assessment which, however, poses a challenge to the buyer as it relies on the access of background information of a country, such as crop production and storage conditions (e.g. weather) and analytical results of goods originating from the respective country. In addition, against the background of low margins in the trade/procurement sector of bulk agricultural commodities, high sampling costs can have a reducing effect on sampling frequency ( $\rightarrow$ Main characteristic of procurement sector). However, variations of analytical results of a trading unit due to different analytical methods between North-west European countries and supplier countries have not only a disconcerting effect on the participants, but must be viewed critically in view of the low margins due to the costs of multiple testing. Further, long wait for the analysis results and the lack of quick tests (e.g. ergot alkaloids) are considered by the experts as not compatible with the overall time pressure that characterizes global commodity flows, especially at ports. In the worst case, waiting for analysis results can lead to two extreme events: It can obstruct or even stop processes, such as a vessel having to wait several days under favourable conditions for mycotoxins at the export port before it can leave ( $\rightarrow$ Disruptions and shifts). On the other hand, due to scheduled delivery times that must be met, the analysis results are available when the goods have already been processed in the feed industry or even fed to livestock. Furthermore, demanding and different infrastructural conditions (such as large flat stores, silos and bulk carriers, different handling systems) make a correct and representative sampling of mycotoxins, which are a challenge due to hotspot building, even more difficult ( $\rightarrow$ Logistics related conditions: Infrastructure).

External controls carried out by authorities or private control bodies also show weaknesses according to the experts. With regard to authority controls, different types of official border control (from no controls, to risk-oriented, to overall controls), different control frequencies and costs within the EU are seen as an impeding factor for commodity flows, as well as the differences in handling food safety issue and corresponding consequences for the actors involved even within a country. On the other hand, the lack of understanding / awareness of the authorities (see Figure 4 Human factor) regarding the role of logistics in food safety is reflected in the control gaps for example in terms of sanitation of discharging facilities and truck compartments. With regard to inspection bodies, the results show that the biggest challenge is to find accredited or certified inspection bodies around the world.

Finally, the greatest weakness in traceability, as the last critical food safety measure identified in this study, is the current gaps along global agri-bulk commodity. In a lowmargin sector, for reasons of efficiency, consolidation (mixing) of agri-bulk commodities from different countries in the export port and commingled storage in the EU port takes place, with the result that traceability back to the producer of the agri-bulk goods or even to the country of origin cannot be guaranteed neither in third countries nor in the EU ( $\rightarrow$ Main characteristics of procurement sector).

\subsection{Logistics Related Conditions}

Global commodity flows are embedded in Logistics related conditions that represent one of the most important critical dimensions for food safety/mycotoxin contamination (Figure 2). Figure 5 shows the breakdown of Logistics related conditions into eight identified influential areas in terms of their importance for food safety. Here we can differentiate between Influential areas that show country or world region-specific differences, such as Infrastructure, Regulations, Weather, Socio-cultural conditions, and Political conditions as well as influential areas that can be interpreted as global drivers such as Market conditions, Technology, and Standards. 


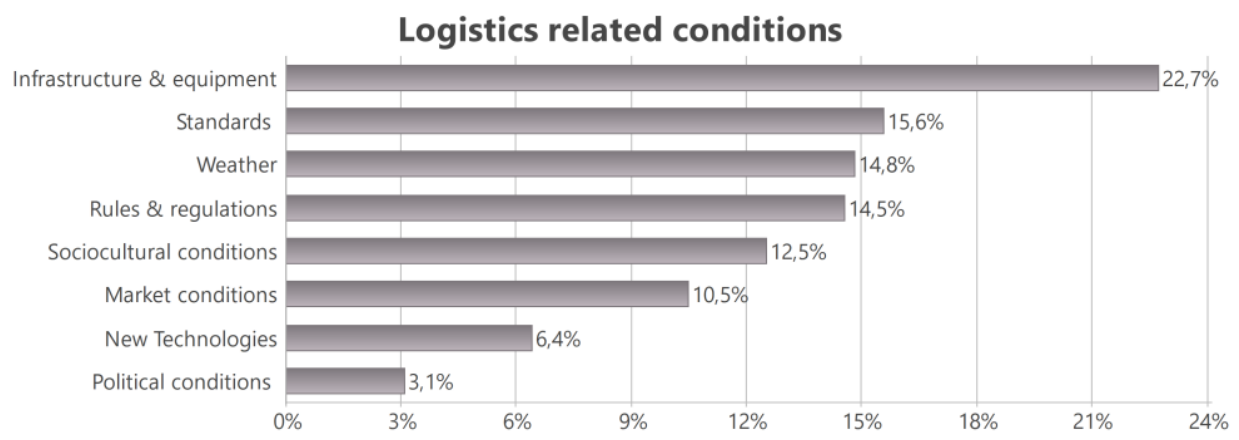

Figure 5 Share of the mention (=coded segments; total code frequency $n=335$ ) of the sub-areas (influential areas in the dimension „Logistic related conditions“) by the interviewed experts.

Although infrastructure proves to be the most critical Influential area, Rules and regulations (14,5\%) and Standards $(15,6 \%)$, which together make up the international food safety regulatory framework, are even the most important influential area. Here, the stated lack of harmonization manifests itself in the diversity of food safety regulations (such as different Maximum Limits (ML) for mycotoxins), as well as the variety and high amount of standards, even within the EU. According to the experts, this constitutes a major barrier to international trade that creates uncertainty among the actors involved and consequently can have a disruptive effect on global commodity flows. In addition to diversity, we identified gaps or inaccuracies in food safety standards and regulations regarding important aspects such as sanitation of transportation modes and handling equipment, that are however relevant for food safety. This is reflected in control gaps of food safety authorities, for instance in the field of preload in trucks or cleanness of handling equipment. On the other hand, inaccuracies in standards regarding sanitation of truck compartments triggers uncertainty among the participants and leads to the fact that "everyone can do what they want" (E2). This weakness is related to the limited efficiency of standards. Hence, many experts consider that they do not cover or influence one of the most important factors in QM, such as the way in which QM is implemented, which is directly linked to the mentality and behaviour of logistics companies, as mentioned above.

With regard to the second most important area of influence, Infrastructure and equipment, the results indicate that a wide range of types and qualities of logistics infrastructure are used in global commodity flows, which can vary from region to region, from country to country, but also within a country. The type and quality level of infrastructure mainly affects the logistics processes having a decisive influence on important mycotoxin-relevant parameters: The type of handling equipment (elevators/ enclosed conveyor belts vs trucks) for instance, has an effect on the duration (discharging rate) of the handling processes and on the environmental conditions. The type of storage facilities (flat storage vs. silos) has an impact on bird infestation and weather-related environmental conditions. Furthermore, holes/leakages in truck compartments and bulk carriers (water tightness hatches of sea vessels) can lead to rain/water infiltration that favours mould contamination. Further, there are huge differences between the quality of ventilation systems of sea vessels / bulk carriers: from modern ventilation systems to no ventilation at all during sea transportation. Finally, the factor of availability of an adequate and sufficient infrastructure along global commodity flows must be considered. Especially in the event of market fluctuations or dynamic shifts of commodity flows that lead to an increased demand in a certain supplier country, logistical bottlenecks can occur. This can include having to use storages that do not meet minimum standards or time delays due to insufficient roads.

Weather does not only play a decisive role for mycotoxin contamination during logistical processes, but it is closely linked to market conditions or fluctuations that are responsible for shifts of global commodity flows. Climate determines to a large extent harvest quantity/condition that control market prices and consequently worldwide demand or flows of agri-bulk commodities.

Changing Political climate (such as the election of a new president, export restrictions) or even trade wars/conflicts between countries also impacts the international flow of agri-bulk commodities. Dynamic shifts not only affect the availability of infrastructure, but also the storage time of agri-bulk commodities at the port and the behaviour of logistics companies and buyers. While the changing origins of agri-bulk may pose challenges for buyers in their risk assessment of new supplier countries and partners/suppliers, the QM of logistics companies suffers from too much stress or too little work. Apart from that, the results show that there are huge country- or word regionspecific differences in the way QM is implemented by logistics companies. Here, different Socio-cultural conditions, especially cultural differences that are reflected in the mentality, play the most important role.

Finally, the relatively low mention of Technology $(6,4 \%)$ reflects the opinion of many experts, that there is still a very limited use of new technologies in the logistics sector that could enhance food safety. In practice, new technologies, such as block chain technology and its improving effect on traceability, sampling innovations (e.g. near-infrared, real-time data) and innovations in the field of monitoring of environmental conditions during storage and transportation (e.g. early warning sensors) do not yet play a role in the broad application.

\subsection{Logistical Processes}

Logistical processes include the sub-areas Interim storage at ports, Up- and unloading, and Transportation (road and sea transportation). As data analysis revealed the multiple mention of critical factors in the different logistical processes, the most important critical factors are presented in an aggregated form in Figure 6. Accordingly, Time or the 
duration of logistical processes was the most frequently cited critical factor related to mycotoxin contamination of agribulk commodities, although it was mentioned in large part in combination with the critical factors Weather and Infrastructure ( $\rightarrow$ Logistics related conditions).

\section{Logistics processes}

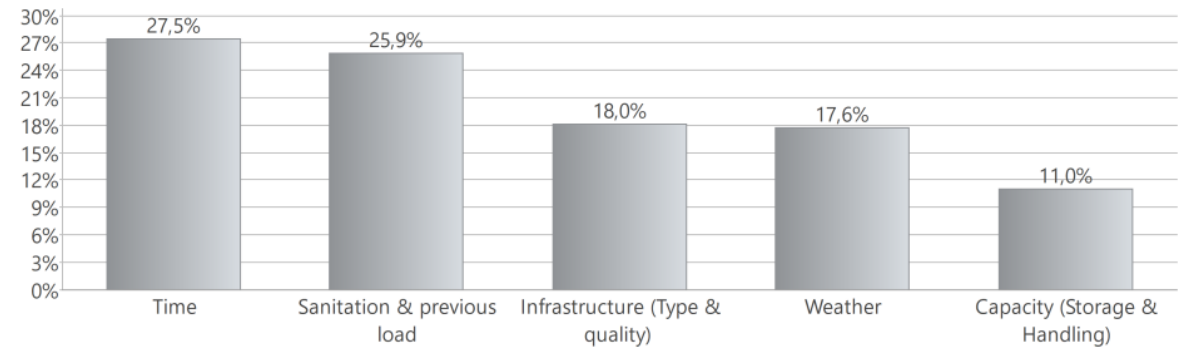

Figure 6 Share of the mention (=coded segments; total code frequency n=292) of aggregated critical factors in the dimension „Logistics processes" by the interviewed experts.

Firstly, this applies in particular to sea transportation. Most experts agree that mycotoxin contamination may occur during sea transportation as the duration of regular transportation in combination with comparatively unfavourable environmental conditions inside the bulk vessel due to poor infrastructure (e.g. shortcomings in the ventilation, leakages of hatches) and varying conditions outside (e.g. change of climate, storms) can lead to condensation inside the bulk carrier which promotes mould contamination. Further, as the business interest of terminal operators is a high rotation of handled goods, ports are generally not prepared for longer storage periods in terms of equipment and expertise. Consequently, the time of interim storage at ports is considered critical in two respects: when the goods are unloaded in rainy conditions or delivered already humid from sea transportation and additionally are unloaded by trucks than by covered conveyor belts. The duration of handling processes is also of importance concerning mycotoxin contamination: the faster the up/unloading process, depending on technical equipment and the volume quantity, the shorter the goods stay in unfavourable conditions of the bulk carrier. Accordingly, large volumes in combination with poor handling equipment, have a negative effect on time and thus promote on mycotoxin contamination. However, in practice especially rainy conditions may be responsible for the fact that the handling processes has to be delayed in the absence of closed handling systems to the disadvantage of food safety.

Next, Sanitation of handling equipment and transportation modes as an important element of a logistics company's QM is proving to be a one of the major challenges in practice according to the frequent mention of this critical factor by the experts. This applies in particular to the inadequate cleaning of truck compartments in accordance with the preload that may lead to unhygienic conditions and increase the risk of to cross-contamination. Finally, the Handling and storage capacity of a port is also evaluated as critical for food safety by the experts. In times of high demand, when storage capacity is limited due to the spatial limitations of ports, different goods/products can be stored without separation for reasons of efficiency, with negative effects on traceability ( $\rightarrow$ Foods safety measures) and with the risk of cross-contamination. On the other hand, a high import rate combined with a low handling capacity can lead to goods staying longer in bulk carriers under unfavourable conditions, if either long queue of bulk carriers exist in front of the port or seagoing vessels are used as a flexible storage facility.

\subsection{Cooperation}

Finally, the results show that Cooperation between the buyer (here: trader or feed industry) and the logistics company must also be considered a critical dimension in terms of food safety in global commodity flows. Figure 7 illustrates the outstanding role of the buyer that determines the Power balance between the buyer and the logistics company with potential consequences for food safety. First of all, as the owner of the goods, the buyer carries responsibility for the safety of the product and that all actors downstream comply with EU food safety regulations, which requires corresponding measures. With regard to food safety, the buyer determines quality and safety specification, draws up a sampling plan within the framework of its HACCP plan, arranges for samples to be taken at the place of origin and along global agri-bulk commodity flows by inspection bodies and in case of the feed industry, takes reserve samples during the acceptance check.

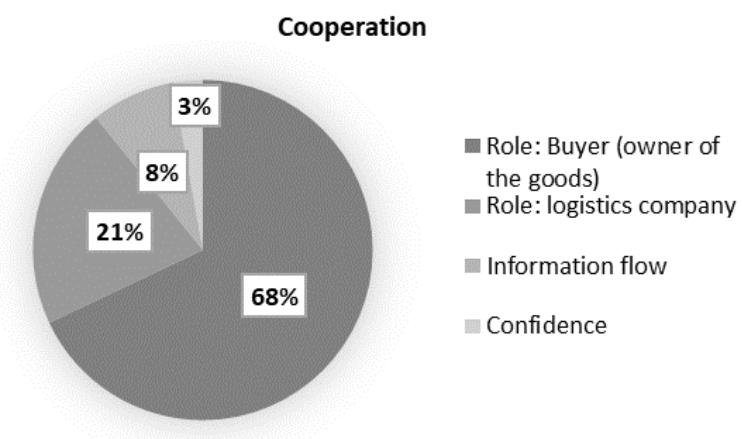

Figure 7 Proportion/share of the mention (=coded segments; total frequency $n=180$ ) by the interviewees for the sub-areas of the dimension "Cooperation“" illustrating the dominant role of the buyer that is relatively more relevant for food safety than the issues of "information flow" and "confidence".

Consequently, the buyer, as the owner of the goods, is in a position to redirect commodity flows or knock the goods, if for example they exceed the allowed Maximum Limit (ML) for contamination. On the other hand, the buyer checks his suppliers/logistics service providers through his own and commissioned audits by inspection bodies and carries out 
supplier evaluations. In summary, the buyer's task is to assess the risks associated with the product and the supplier/service provider as part of their HACCP plan and at the same time to promote the QM of logistics service providers, e.g. through training or strict requirements. Secondly, as a customer the buyer decides not only on the type (type of transport means, type of storage facilities), but also on the quality of logistics service. Theoretically this means that the buyer has the possibility to choose between a bandwidth of logistics providers in terms of their QM. In practice, it depends on the buyer's willingness to pay more, their financial resources, market prices of agri-bulk commodities and ultimately on the availability of logistics companies with good QM that is not always guaranteed in the event of dynamic shifts of global commodity flows. Similarly, the buyer can choose to work with the "right" inspection body, but here too it is a challenge to find accredited / certified inspection body around the world. Finally, the cargo owner decides on the conditions during the logistic processes that are relevant for a potential mycotoxin contamination. The buyer determines for example the storage conditions and takes the key decision whether to unload a bulk vessel in rainy conditions or not. Finally, the cargo owner decides how long the goods will be temporarily stored at the port, which also depends on the market conditions.

In contrast, logistics companies carry out the buyer's instructions. Their main task is to keep the goods from A to $\mathrm{B}$ in the same quality which includes keeping the agreed storage and transport conditions by control measures within the framework of their QM. Product control is limited to visual inspection only. This illustrates that the logistics company who is closest to the goods and therefore can directly uncover discrepancies regarding food safety, is strongly limited in his actions by the existing power balance to the buyer. In summary, the results clearly show that the performance of the logistics company with regard to food safety always depends to a considerable extent on the buyer's attitude and actions.

\section{DISCUSSION}

By investigating the case of potential mycotoxin contamination of agri-bulk commodities along global commodity flows, we were able to identify eight critical dimensions for food safety (Food safety measures, Logistical processes, Human factor, Disruptions and shifts, Logistics related conditions, Cooperation, Main characteristics of the procurement sector, and Port characteristics) and corresponding critical factors inside and outside global commodity flows. Furthermore, we have identified and visualized interrelationships between these dimensions and shown which dimensions and critical factors tend to be more important in the context of food safety. The close and complex interconnectedness of the different dimensions of global commodity flows shows very clearly that potential food safety threats and risks along global commodity flows are not solely attributable to the logistics sector per se, and the associated actors and processes involved. Rather, the Food safety measures and Logistics related conditions that vary from country to country as well as the Cooperation between the buyer and logistics company have proven to be a major challenge for food safety along global commodity flows.
Among the Food safety measures that have to be applied along the global commodity flows according to the EU food safety regulation, we have found that QM of logistics companies is one of the biggest challenges. This is not striking against the background of the general assessment that the management factor causes up to $85 \%$ of quality and food safety issues or concerns (Ryan, 2017). The CODEX Alimentarius Commission CAC highlights that the implementation of HACCP food safety management system and an overall risk-based management of food safety / quality remains very challenging along the whole food chain (Codex Alimentarius Commission, 2016). In the present study, we have found plausible explanations for the logistical part of global agri-bulk commodity flows. Global commodity flows, which largely consist of logistics and trade, are generally characterised by strong competition (Christopher and Holweg, 2011). As a low margin sector, this applies in particular to the procurement of agri- bulk commodities as exemplified by one of the experts: "When we are talking about huge globally traded commodities such as wheat, corn, soybean meals, and so forth - then we are talking about mass markets where margins are generally always very low and eventually even not existing" (E.7). Consequently, efficiency and effectivity constitute the major targets in the cooperation between trading partners and the coordination of logistical processes with the result that commodity flows as part of global supply chains are as a matter of principle not designed in agreement with risk evaluation and risk assessment (Manzini and Accorsi, 2013).

In addition to economic pressures, time pressure and spatial capacity limits also encourage the pursuit of efficiency in this sector. In this context, ports, as the most important hubs, are the focus of attention. Here, the efficiency factor can affect food safety in two ways: If port capacity does not keep pace with trade growth or exportimport rates due to lack of efficiency, ports may become congested, leading to an increased risk of deterioration in the quality and safety of goods (Schieck, 2008). In this case, the transportation flow is impaired, which may result in agribulk having to remain in the bulk ship under unfavourable conditions for a longer period, as this study has confirmed. On the other hand, for efficiency reasons, the separation of different qualities and risk categories at the import harbour remains a challenge due to the general spatial limitations in ports. Therefore, extended port storage must be viewed critically for food safety. The situation is similar at the export port at the beginning of global agri-bulk commodity flows: In order to reduce transport costs and maximise profit, it is also necessary to combine / mix agricultural goods of different origin and different quality before sea transportation.

In general, global competition forces traders and procurers from the feed and food industry to buy at low prices on the world market, taking risks or trying to manage them through risk assessments when sourcing from distant countries. For the same reason, traders or procurers often do not choose the "safest option" when selecting logistics companies. On the contrary, savings are often made at the logistics company, the last link in the chain, especially during "crisis conditions" such as high market fluctuations. Additional services and more transparency in terms of quality and safety, which are associated with additional expenses for the logistics provider, are therefore less in 
demand and accordingly not honoured by the customer. In this regard, the claim expressed by one of the experts that "logistics companies who are transparent should be rewarded by the industry for their transparency, for their openness" (E.2) seems justified. Consequently, due to the low demand / orders, additional services with regard to food safety are even accompanied by potential economic losses for the logistics company. This transfer of economic pressure from the trader or procurer to the logistics company often leads to the logistics company limiting his QM in order to make any profit at all. These prevailing economic circumstances have a direct impact on the attitude and behaviour of logistics providers with regard to food safety. The statement "I think the biggest risk [for food safety] is the human factor" (E.5) confirms the finding of the present study identifying the Human factor as an important critical dimension for food safety.

This reflects the importance of the way the QM is implemented. According to the GMP standard, a reliable QM system requires pro-active action, which is expressed in a series of preventive measures (Hartog, 2017). The lack of incentives for prevention can be seen as a reason why, despite the various QM and certification systems already in place, logistics processes remain a challenge in terms of quality assurance. However, the present study also shows that there are considerable differences between countries in terms of QM implementation, which is related to a different understanding of quality in the individual countries. This should be a particular focus of attention in international trade (Baaken and Lehnen, 2015). On the other hand, the economically challenging conditions often lead to the fact that especially small logistics companies that do not meet the requirements and drop out or that not all participants in the chain are certified. With a high number of actors, as is often the case with global commodity flows, the latter can quickly lead to a lack of transparency or chain fragmentation. In terms of food safety, this is seen as a challenge, as "the whole chain is as strong as the weakest link" (E.1). However, in the course of globalization there is a trend towards chain integration as an opposing development with respect to chain fragmentation. The focus here is on global corporations that may own an entire supply chain and, according to the experts, dispose of a very good QM systems. Moreover, they are generally better positioned in terms of infrastructure and technology and transfer such capacities, as well as the understanding of quality, to emerging and developing countries as "the more integrated the chain is, the more important the quality becomes" (E.10). Nevertheless, as competition intensifies, the need for companies to use supply chain integration practices will increase, requiring a flexible organizational structure (Porter, 2019). In general, however, there is a common lethargy in the logistics sector with regard to investments in the latest technologies that are relevant for food safety (e.g., block chain technology, sampling technology). The low relevance of technology is reflected in the low frequency of mentioning in this study. The fact that new technologies, in particular of the Industry 4.0 (e.g., block chain) require financial resources that a large part of the logistics industry does not have, once again illustrates the economic pressure on the logistics sector. In addition to the cost factor, the lack of initiative from top management, the unwillingness of stakeholders to accept change and to share data, and insufficient interoperability between partner systems may be other reasons why the use of these technologies is scant (de Vass et al., 2021).

The explanations demonstrate very well that under the current system the logistics sector can neither be held solely responsible for food safety risks nor is it capable of independently ensuring the socially desired level of food safety. Besides the economic pressure, this is also reflected by the power balance between buyer and logistics companies. Statements like "This can only be solved as a whole sector" (E.13) and "we need to work and team up together" (E.16) illustrate that the problem can only be solved integratively as an entire supply chain / industry. It should be considered whether the value of food safety as a co-determining element for pricing could provide incentives to invest more in corresponding measures and technology. In this context, a higher willingness of consumers to pay more for the product would have a positive effect regarding food safety on the entire chain.

Furthermore, it is the international food safety governance and the resulting food safety measures applied along global agri-bulk commodity flows themselves which, due to current weaknesses, pose an indirect threat to food safety (or mycotoxin contamination). This is supported by the results to the extent that, Regulations and Standards in the dimension Logistics related Conditions represent a greater challenge for food safety according to the code frequency than, for example, Infrastructure or Weather. In particular, the frequently cited great variety and quantity of regulations and standards play a key role, which in the literature is also referred to as the "fragmentation of the multilateral international food safety regime" (Alemanno, 2015). Since 2000 with the paradigm shift in European food safety regulations, the standards for food safety and quality have grown immensely, with the result of a great variety of safety management practices (Aruoma, 2006). Besides the multilateral organizations like FAO, WHO and OIE, the private setting industry and plenty of NGOs have dedicated themselves to the field of food safety standards. On the other hand, the lack of harmonization at the level of national regulations is shown by the fact that mycotoxins, especially aflatoxins, are differently regulated in approximately 100 countries in terms of the maximum levels (ML) (van Egmond and Jonker, 2004). The different sets of rules and standards as well as the amount of standards beyond food safety, such as sustainability and GMO-free standards, pose a challenge for the coordination between the participants in global commodity flows (van der Vorst et al., 2009). The consequences are far-reaching and can manifest themselves by interruptions of commodity flows and an increased uncertainty of comprehension among participants. This may explain a certain weariness by some experts: "But they all have their own level and they all want to be unique. It would be good if there were a few less [standards] that would save a lot of cost [...] I think it would also reduce the risk, if something goes wrong. [..] by so many schemes, a lot of time is wasted on understanding where the differences are" (E.16). Even in the literature it is mentioned that the current lack of harmonization of a global international food system can be blamed for food safety accidents (Alemanno, 2015). This has triggered an ongoing debate over the establishment of a global food safety regime in order to overcome the current institutional fragmentation. In addition to the fragmentation, it is also stated that the current global food 
safety system appears to be incomplete and presents several gaps (Alemanno, 2015). The present study confirmed current gaps for instance in the field of sanitation/cleaning of truck compartments, where inaccuracies lead to the fact that "everyone can do what he wants because no one is also off the mark, because nothing is defined" (E.2).

In this context, the study has shown that there are no uniform and precisely defined food safety practices in the logistics sector required by standards or regulations, neither globally, EU-wide nor nationally. Consequently, it is up to the client of logistics services that "ultimately determines what happens and what does not happen" (E.18), e.g., the feed industry, to enforce precise quality and safety requirements at the logistics company they work with, which is perceived as burdensome task by some experts. Consequently, the present study emphasizes the importance of harmonizing regulations and standards in order to avoid disruptions in global commodity flows that could affect food safety and has uncovered gaps and inaccuracies in food safety standards and regulations related to the logistics sector, which are however relevant to food safety. In the long term, it would therefore be advisable not only to revise the standards with a view to harmonization, but also to fill in the gaps with greater precision in order to achieve greater clarity and certainty for participants on the one hand and greater transparency in the food safety practice (e.g. sanitation) on the other.

Furthermore, the study has revealed that Food safety measures and corresponding requirements in their current form are not adapted to the complexities of global agri-bulk commodity flows, which poses a challenge to the participants and thus indirectly a risk to food safety. According to the results, it is above all the area of Sampling and analysis, which represents one of the greater concerns in terms of mycotoxin contamination / food safety. It is well known that the heterogeneous distribution or hot-spot formation of mycotoxin production makes representative sampling a major challenge, which is further complicated by the large quantities of agri-bulk and by the difficult and varying infrastructural conditions at harbors and in bulk vessels. In addition to this heterogeneity, the study showed that different analysis methods applied along global commodity flows can also lead to a variability of the analysis results within a lot and at different stages of the commodity flow. In this context, the WHO confirms that laboratory capacities outside Europe are less advanced and surveillance systems less developed (World Health Organization WHO, 2015). Against this background, it proves difficult to meet the desired requirement to transport and store uniform agribulk regarding its risk category which is based on analytical results. In fact, due to the challenges mentioned above, different qualities are often mixed together at the export port and sampled afterwards. Finally, the high sampling costs in a sector with very low margins can lead to a lower sampling frequency, which can also have a negative impact on food safety. However, the frequency with which the factor Sampling and Analysis is mentioned in connection with global commodity flows indicates that further studies should take a closer look at this. At the institutional level, the problem of different analytical methods has already been recognised. Efforts are being made by food safety authorities to improve the comparability of the analysis methods and their results, with the aim of further harmonization. There is also a need to understand and quantify sampling uncertainties under varying conditions of mycotoxin contamination in cereal shipment (Bourgeois and Lyman, 2012). For the practice in global commodity flows research, advances in sampling and analysis could mean less sampling costs, more precise sample plans, more security when mixing agri-bulk from different origins to certain risk categories at the export harbour as well as better adaptation of suitable transportation conditions on the bulk vessels.

Another frequently mentioned food safety measure that is not adapted to the real conditions of global agri-bulk commodity flows is Traceability, which as an EU obligation requires recording of trace-back and trace-forward data of the trading unit by all supply chain participants. However, the study demonstrates that traceability is difficult to implement especially in two points of global commodity flows: at consolidation at the export harbour and at commingled storage in the import harbour. In order to maximise profit, grain storage bins for instance can contain grain from many different sources with the consequence that the identity of the lot is not preserved (Thakur and Hurburgh, 2009). In this context, efforts in the field of analysing the authenticity/origin of feed stuff by fingerprint technology especially in the field of agri-bulk commodities, can be very useful (Achten et al., 2019). Apart from this, traceability as covered by EU food safety regulation has been evaluated in literature as a short-sighted concept (Ryan, 2017). Therefore, in addition to the traceability of the trading unit, other important aspects would have to be traced. Current development of traceability tools moves in the direction to achieve transparency/visibility of global supply chains at various levels such as transportation modes (e.g. location, route), parameters of food commodities (e.g. temperature), procedures (e.g. sanitation) and environmental conditions during logistical processes (e.g. temperature, humidity) (Ryan, 2017). Moreover, information systems are being developed that aim at combining safety, sustainability and efficiency in supply chains that require integrating different data type from different data sources (Manzini and Accorsi, 2013). In general, in the area of traceability, blockchain seems to be the most promising and applicable technology. But other potential applications are also seen in standards compliance and supply chain integration (Batwa and Norrman, 2020).

Further, the study revealed weaknesses in official authority controls in the logistics sector reflecting the gaps identified in food safety regulations mentioned above. As a result, in practice there are fewer authority controls in logistical areas important for food safety, such as the type of sanitation or the quality condition of transportation modes. These control gaps lead to the assumption that food safety authorities often have a lack of understanding of the importance of logistics for food safety. The reason can be seen in an expert's statement that logistics "is, or always has been, a very opaque industry" (E.2). The lack of knowledge and understanding is also reflected in new regulations and respective requirements, e.g., in the field of modified mycotoxins. On the one hand, modified or "masked" mycotoxins represent an emerging issue which needs to be addressed as they can lead to underestimation of the mycotoxin content of commodities due to analytical overlooking (Nakagawa, 2016). On the other hand, rapid and affordable tests for masked mycotoxins are still lacking, 
which many experts consider impractical as it can hinder the flow of agricultural commodities and also increases economic pressure in the industry. This highlights the problem all the more that new requirements are decided on by authorities where little knowledge of real-life practice prevails. The challenge is therefore to establish new regulations and corresponding requirements that can be linked to practice without creating an additional "burden" for the participants. In summary, it is important to question and adapt current food safety measures and requirements with regard to their practicability, so that they do not impede global commodity flows and significantly reduce efficiency. Consequently, this would increase the acceptance and willingness of the stakeholders involved to take food safety measures. For this purpose, feedback from the economic operators is important, i.e., food safety authorities must cooperate more closely with the trade and logistics industry, especially when new regulations are imposed. As long as there are no fundamental changes in this regard, the question arises whether the identified weaknesses in the area of regulations and standards and resulting food safety measures, which are also seen as a risk to food safety, need to be integrated into current systems of risk assessment or early risk identification. However, more studies are needed in this area to verify these results.

\subsection{Limitations of The Study}

The sample size of 18 interviews with 24 experts is rather limited for generalizability or representativity. The aim of the study was therefore to show tendencies and plausible causal relationships and explanations. However, the study has revealed differences in perception and even contradictions between the experts. The different roles of the interviewed experts have an influence on the perception and depending on the point in the flow of goods from which they act, they see the weak points somewhere else. This shows how important it is to survey different groups of actors in a complex sector such as logistics and trade. Further actors of interest could be customs or independent inspection bodies as well as further logistics actors such as transportation companies (e.g., road transportation, sea vessels). The sometimes large discrepancy in perception or the lack of consensus among the experts can be seen both as a legitimisation for the research field and as an argument for further research.

The qualitatively determined risk for food safety along global commodity flows in the present case study must be evaluated under two caveats. First, the influence of global commodity flows, especially logistics, on mycotoxin contamination of agri-bulk commodities must be considered in relation to the other supply chain stages, such as primary production and processing, in order to counteract a distorted perception of risk. Much research on the development of management or prevention tools for mycotoxin contamination is conducted in the area of crop production and post-harvest techniques/storage; however limited research was conducted in the field of the logistics sector to date.

Another caveat regarding the interpretation of the results refers to the fact that several experts hold additional knowledge and experience in food sector areas other than agri-bulk commodities, e.g. fruits and vegetable and not all experts consulted, especially from the field of logistics, had sound knowledge about mycotoxins. Therefore, the questions had to be asked in a general food safety context and, finally, the identified critical factors may not be limited to the case of mycotoxin contamination of agri-bulk commodities.

Further, the identified context factors (such as cooperation, main characteristics of procurement sector) have a general influence on food safety and not only on mycotoxins. In addition, based on the expertise and experience of some experts in the food sector, the actual relevance of the identified critical factors for mycotoxins and agri-bulk for feed use should be verified in further studies. Moreover, it would also be advisable to narrow down the topic in further studies to focus on individual aspects.

\section{CONCLUSION}

A first explorative or empirical look into the complex and opaque area of logistics within global commodity flows from a food safety perspective has been conducted by interviewing various experts from the European and global procurement and logistics sector of agri-bulk commodities that include actors form trade, logistics, the feed industry as well as from the field of regulations and standards on the case of mycotoxin contamination of agricultural raw materials. The present study uncovered trends for relevant critical dimensions and factors for mycotoxin contamination and food safety risks in general along global commodity flows and provide plausible correlations and explanations or backgrounds for this. In this way, the study has demonstrated that, due to the close interconnection of logistics with the trade and the feed industry (2) as well as with its different environments, logistics cannot be considered separately in terms of food safety. In addition to the already assumed critical factors for food safety in logistics processes, it is above all the food safety measures (such as Quality Management of the logistics company, Sampling and analysis, External controls and Traceability) not adapted to practice and varying Logistics related conditions in global commodity flows that pose a challenge to food safety (4). Further, we have found that the conditions prevailing in the trade and logistics sector, such as competitive pressure, time pressure and low margins, are in conflict with food safety requirements, which not only cost time and money (e.g. sampling), but also fail to deliver the expected efficiency due to a number of gaps (e.g. sanitation and traceability) and irregularities (e.g. diverse analytical methods and regulations). In particular, economic pressure combined with difficult working conditions resulting in a high fluctuation of workers in the logistics sector as well as varying sociocultural conditions influence human factors such as mentality and diligence which can have a negative impact on the implementation of QM. The strong economic pressure further leads to a general inertia in the logistics and trade sector to invest in the latest technologies (e.g. Block chain) that could influence food safety in a positive way. Furthermore, the interaction with complex logistics related conditions, which are characterized by a great variety of regulations, standards and of the type and quality of infrastructure on the one hand and dynamics, especially market fluctuations, on the other, can have a disruptive effect on global commodity flows $(3,4)$. 
The fact that the sector is highly fragmented and complex can be seen not only in the diversity of the logistics related conditions, but also in the divergent statements of the experts regarding the certification and level of QM of logistics service providers. The case study therefore makes no claim as for the representativeness of the data or even an evaluation/ranking of the critical dimensions and factors determined. Instead, it highlights the importance to improve knowledge in this field of research. The case study will support further studies by providing potential relevant dimensions and factors critical for food safety along global commodity flows. The frequency and variance of the data should be interpreted as an indication that individual dimensions or critical factors should be investigated and further verified inclusive of quantitative studies. In the long term, current approaches to risk assessment and early risk identification, including innovative models and tools that analyse complex supply chains are to be supplemented by elements from the area of global commodity flows. In conclusion, the study can be seen as a pioneering work since the topic still has a lot of undiscovered research potential.

\section{ACKNOWLEDGEMENT}

One of the major plus points of the case study was the great willingness of the experts to cooperate, their competence, openness, time and wealth of experience. In addition, the output could be increased enormously by an open and friendly discussion atmosphere and the possibility to conduct the majority of the interviews personally on site. Special thanks are due to the organizations COCERAL, UNISTOCK EUROPE and FEFAC, who contributed to a large extent to the success of the study through their helpfulness, their expertise and their mediation to experts.

\section{REFERENCES}

Achten, E., Schütz, D., Fischer, M., Fauhl-Hassek, C., Riedl, J., \& Horn, B. (2019). Classification of Grain Maize (Zea mays L.) from Different Geographical Origins with FTIR Spectroscopy - a Suitable Analytical Tool for Feed Authentication? Food Analytical Methods, 12(10), 2172-2184.

Alemanno, A. (2015). The Multilateral Governance Framework for Food Safety: A Critical and Normative Overview. In Food safety, market organization, trade and development (pp. 9-43), Springer, Cham.

Aruoma, O. I. (2006). The impact of food regulation on the food supply chain. Toxicology, 221(1), 119-127.

Baaken, H.-J., \& Lehnen, J. (2015). Nachhaltige Futtermittelwirtschaft im Kontext einer globalen Rohstoffbeschaffung. Journal Fur Verbraucherschutz Und Lebensmittelsicherheit-Journal of Consumer Protection and Food Safety, 10(2), 179-184.

Battilani, P., \& Leggieri, M. C. (2015). Predictive modelling of aflatoxin contamination to support maize chain management. World Mycotoxin Journal, 8(2), 161-170.

Batwa, A., \& Norrman, A. (2020). A framework for exploring blockchain technology in supply chain management. Operations and Supply Chain Management: An International Journal, 13(3), 294306.
Bourgeois, F. S., \& Lyman, G. J. (2012). Quantitative estimation of sampling uncertainties for mycotoxins in cereal shipments. Food Additives \& Contaminants: Part A, 29(7), 1141-1156.

Buchholz, U., Bernard, H., Werber, D., Böhmer, M. M., Remschmidt, C., Wilking, H., Deleré, Y., an der Heiden, M., Adlhoch, C., \& Dreesman, J. (2011). German outbreak of Escherichia coli O104: H4 associated with sprouts. New England Journal of Medicine, 365(19), 1763-1770.

Christopher, M., \& Holweg, M. (2011). " Supply Chain 2.0": managing supply chains in the era of turbulence. International Journal of Physical Distribution \& Logistics Management, 41(1), 63-82.

Codex Alimentarius Commission. (2016). Joint FAO/WHO Food Standards Programme, FAO/WHO Coordinating Committee for Europe, Food Safety and Quality Situation in Countries of the Region,. Astana, Kazakhstan

de Vass, T., Shee, H., \& Miah, S. (2021). IoT in Supply Chain Management: Opportunities and Challenges for Businesses in Early Industry 4.0 Context. Operations and Supply Chain Management: An International Journal, 14(2), 148-161.

De Wolf, E., Madden, L., \& Lipps, P. (2003). Risk assessment models for wheat Fusarium head blight epidemics based on within-season weather data. Phytopathology, 93(4), 428-435.

Garcia-Cela, E., Kiaitsi, E., Sulyok, M., Krska, R., Medina, A., Petit Damico, I., \& Magan, N. (2019). Influence of storage environment on maize grain: $\mathrm{CO} 2$ production, dry matter losses and aflatoxins contamination. Food Additives \& Contaminants: Part A, 36(1), 175-185.

Gläser, J., \& Laudel, G. (2009). Experteninterviews und qualitative Inhaltsanalyse: als Instrumente rekonstruierender Untersuchungen, Springer, Wiesbaden.

Göpfert, I., \& Braun, D. (2013). Internationale Logistik in und zwischen unterschiedlichen Weltregionen, Springer Gabler, Wiesbaden.

Hartog, J. d. (2017). Early Warning System and Tracking \& Tracing for feed safety. FeedMagazine/Kraftfutter, 1112.

Kos, J., Lević, J., Đuragić, O., Kokić, B., \& Miladinović, I. (2014). Occurrence and estimation of aflatoxin M1 exposure in milk in Serbia. Food Control, 38, 41-46.

Kruse, H. (2015). Food safety in an international perspective. Journal Fur Verbraucherschutz Und Lebensmittelsicherheit-Journal of Consumer Protection and Food Safety, 10(2), 105-107.

Loosen, W. (2016). Das Leitfadeninterview-eine unterschätzte Methode. In Handbuch nicht standardisierte Methoden in der Kommunikationswissenschaft (pp. 139-155), Springer, Wiesbaden.

Manzini, R., \& Accorsi, R. (2013). The new conceptual framework for food supply chain assessment. Journal of Food Engineering, 115(2), 251-263.

Marucheck, A., Greis, N., Mena, C., \& Cai, L. (2011). Product safety and security in the global supply chain: Issues, challenges and research opportunities. Journal of Operations Management, 29(7-8), 707-720. 
Marvin, H. J. P., Kleter, G. A., Frewer, L. J., Cope, S., Wentholt, M. T. A., \& Rowe, G. (2009). A working procedure for identifying emerging food safety issues at an early stage: Implications for European and international risk management practices. Food Control, 20(4), 345-356.

Mayring, P. (2004). Qualitative content analysis. In A companion to qualitative research (Vol. 1, pp. 159176), SAGE Publications Ltd, London.

Nakagawa, H. (2016). Research on mycotoxin glucosides (masked mycotoxins). JSM Mycotoxins, 66(1), 21-25.

Noteborn, H., Ooms, B. W., \& de Prado, M. (2005). PanEuropean Proaktive Identifi cation of Emerging Risks in the Field of Food Production. Project ERANET SSA PERIAPT, Financed by the European Commission in the 6th FP. VWA, the Hague, The Netherlands.

Patton, M. Q. (2014). Qualitative research \& evaluation methods: Integrating theory and practice, SAGE Publications, Inc., Thousand Oaks.

Pigłowski, M. (2019). Comparative analysis of notifications regarding mycotoxins in the Rapid Alert System for Food and Feed (RASFF). Quality Assurance and Safety of Crops \& Foods, 11(8), 725-735.

Porter, M. (2019). Supply chain integration: Does organizational culture matter?. Operations and Supply Chain Management: An International Journal, 12(1), 49-59.

Ryan, J. M. (2017). Guide to Food Safety and Quality During Transportation: Controls, Standards and Practices, Academic Press, Cambridge.

Schaarschmidt, S., \& Fauhl-Hassek, C. (2021). The fate of mycotoxins during secondary food processing of maize for human consumption. Comprehensive Reviews in Food Science and Food Safety, 20(1), 91-148.

Schieck, A. (2008). Internationale Logistik: Objekte, Prozesse und Infrastrukturen grenzüberschreitender Güterströme, Oldenbourg Verlag, München.

Singh, P. J., \& Power, D. (2009). The nature and effectiveness of collaboration between firms, their customers and suppliers: a supply chain perspective. Supply Chain Management: An International Journal, 14(3), 189-200.

Staake, R. (1994). Case Studies. Handbook of qualitative research, SAGE Publications, Inc., Thousands Oaks.

Thakur, M., \& Hurburgh, C. R. (2009). Framework for implementing traceability system in the bulk grain supply chain. Journal of Food Engineering, 95(4), 617626. van Asselt, E. D., Meuwissen, M. P. M., van Asseldonk, M. A. P. M., Teeuw, J., \& Van der Fels-Klerx, H. J. (2010). Selection of critical factors for identifying emerging food safety risks in dynamic food production chains. Food Control, 21, 919-926.

Van der Fels-Klerx, H., Dekkers, S., Kandhai, M., Jeurissen, S., Booij, C., \& De Heer, C. (2010). Indicators for early identification of re-emerging mycotoxins. NJAS Wageningen Journal of Life Sciences, 57(2), 133-139.

Van der Fels-Klerx, H., Kandhai, M., Brynestad, S., Dreyer, M., Börjesson, T., Martins, H., Uiterwijk, M., Morrison, E., \& Booij, C. (2009). Development of a European system for identification of emerging mycotoxins in wheat supply chains. World Mycotoxin Journal, 2(2), 119-127.

van der Vorst, J. G. A. J., Tromp, S.-O., \& Zee, D.-J. v. d. (2009). Simulation modelling for food supply chain redesign; integrated decision making on product quality, sustainability and logistics. International Journal of Production Research, 47(23), 6611-6631.

van Egmond, H. P., \& Jonker, M. A. (2004). Current situation on regulations for mycotoxins. JSM Mycotoxins, 2003(Supp13), 1-15.

Webb, M. (2015). Overview of food safety standards. In Food safety, market organization, trade and development (pp. 45-58), Springer.

Weiser, A. A., Thöns, C., Filter, M., Falenski, A., Appel, B., \& Käsbohrer, A. (2016). FoodChain-Lab: a trace-back and trace-forward tool developed and applied during food-borne disease outbreak investigations in Germany and Europe. PLoS One, 11(3).

Wentholt, M., Rowe, G., König, A., Marvin, H., \& Frewer, L. (2009). The views of key stakeholders on an evolving food risk governance framework: Results from a Delphi study. Food Policy, 34(6), 539-548.

World Health Organization WHO. (2015). Complex food chain increases food safety risks. Retrieved from https://www.euro.who.int/en/mediacentre/sections/press-releases/2015/03/complex-foodchain-increases-food-safety-risks

Yin, R. K. (2013). Case study research: Design and methods, SAGE publications, Inc., Thousand Oaks.

Zupaniec, M., Schafft, H., Pieper, R., Lindemann, A.-K., \& Mader, A. (2020). A conceptual framework for the identification of food safety risks in global commodity flows exemplified by agricultural bulk commodities. Manuscript submitted for publication. 


\section{APPENDIX 1: Identified critical dimensions, sub-areas and factors for mycotoxin contamination and food safety risks in global agri-bulk commodity flows with the focus on logistics.}

\begin{tabular}{|c|c|}
\hline $\begin{array}{c}\text { Sub areas of Critical } \\
\text { Dimension }\end{array}$ & Critical Factor \\
\hline \multicolumn{2}{|r|}{ Logistical Processes } \\
\hline Interim Storage at ports & $\begin{array}{l}\text { - Storage time: Ports are generally not specialised (equipment, expertise) for longer storage periods } \\
\text { - Storage capacity: Due to spatial limitations, problematic in time of big demands } \\
\text { - Type of storage facilities: Flat storage (warehouse) has to face more challenges (animals, leakages) than } \\
\text { - } \quad \text { vertical storage (silo) } \\
\text { - } \quad \text { Conitoring / control: Critical especially at longer storage } \\
\text { - Ventilation: Not always guaranteed and critical at longer storage }\end{array}$ \\
\hline Up - and unloading & $\begin{array}{l}\text { - Time: In extended cases, goods remain in sea vessel under unfavourable conditions } \\
\text { - Discharging facilities: Covered belt systems are better than trucks concerning moisture damage } \\
\text { - Weather: Rainy conditions delay loading and cause damage of the goods by moisture } \\
\text { - } \quad \text { Hatches (open/closed): Speed at which the ship's hatches close under rainy conditions is relevant for } \\
\text { preventing moisture damage } \\
\text { - Different products: In busy times, the same equipment can be used for different products } \\
\text { - Speed of grain falling: Correlates with the height of the handling cranes and may lead to grain damage } \\
\text { - } \quad \text { Sanitation: Using same discharging facilities for different products without sanitation } \\
\text { - } \quad \text { Pier un-/ uploading: Ground contact over the pier (footbridge) }\end{array}$ \\
\hline Transportation -Truck & $\begin{array}{l}\text { - Sanitation: Critical if not carried out according to the preload (cross-contamination) } \\
\text { - } \quad \text { Driver: Critical in terms of behaviour, education and food safety awareness } \\
\text { - } \quad \text { Registrations: No official registrations of truck companies (esp. food industry) } \\
\text { - } \quad \text { Cover of the trucks: No covering of the trucks under rainy conditions (esp. third countries) } \\
\text { - Time: Critical when transportation takes longer than three days due to bigger distances (esp. third countries) } \\
\text { - } \quad \text { Poor maintenance: Moisture ingress in case of leakage (e.g. through cracks) }\end{array}$ \\
\hline $\begin{array}{l}\text { Transportation - } \\
\text { Sea vessels }\end{array}$ & $\begin{array}{l}\text { - Time: Critical at several weeks if not ventilated } \\
\text { - Poor maintenance of hatches: Water entering the holds due to leakages } \\
\text { - Weather and climatic changes: Increase risk of condensation inside bulk carriers } \\
\text { - } \quad \text { Ventilation: Poor ventilation systems up to no ventilation } \\
\text { - Sanitation: Proper cleaning of sea vessels is challenging due to infrastructure } \\
\text { - Training: Good training of the crew, e.g. in terms of proper ventilation } \\
\text { - Monitoring: Challenge in controlling environmental conditions (e.g. temperature) }\end{array}$ \\
\hline \multicolumn{2}{|r|}{ Food Safety Measures } \\
\hline Sampling \& Analysis & $\begin{array}{l}\text { - Sampling frequency: Sampling plan depending on a country's risk category and sampling costs } \\
\text { - Analytical methods: Diversity of analytical methods and high incertitude } \\
\text { - Availability of accredited labs: Challenge in finding accredited labs all over the world } \\
\text { - Analytical results: Duration and variation of analytical results } \\
\text { - } \quad \text { Quick tests: Lack of reliable quick tests (e.g. Ergotalkaloide, masked mycotoxins) } \\
\text { - Analysis at origin: Important to gain information on quality/safety of the product to adjust transportation } \\
\text { - } \text { conditions and to mix goods of similar quality } \\
\text { - } \text { stopresent, bulk carriers) and the heterogeneous distribution of mycotoxins (nest formation) }\end{array}$ \\
\hline QM Logistics Company & $\begin{array}{l}\text { - Company size: The smaller a company, the fewer resources it normally has } \\
\text { - Internationalisation: Correlates with the company size, i.e. international companies are more flexible due to } \\
\text { more resources } \\
\text { - } \quad \text { Training and updates: Proper Training and regular updates on changes in standards, regulations } \\
\text { - } \quad \text { Investments: Lack of investments, e.g. in technology (traceability), transportation mode } \\
\text { - Quality manager: Quality manager / department at place often correlates with company size }\end{array}$ \\
\hline Traceability & $\begin{array}{l}\text { - Gaps: No identification of the country of origin nor the raw material producer } \\
\text { - Consolidation: Mixing goods of different qualities and origins at the export harbour } \\
\text { - Commingled storage: Mixing of goods of different qualities and origins at the import harbour } \\
\text { - High flow rate in silos } \\
\text { - Technology: Lack of technological support, e.g. integrated systems }\end{array}$ \\
\hline
\end{tabular}




\begin{tabular}{|c|c|}
\hline \multirow{2}{*}{$\begin{array}{c}\text { Sub areas of Critical } \\
\text { Dimension }\end{array}$} & Critical Factor \\
\hline & $\begin{array}{l}\text { - Certification: Traceability is linked to certification. Not all actors involved are certified } \\
\text { - } \quad \text { Costs: Accurate and complete traceability of agricultural commodities increase costs } \\
\text { - } \quad \text { Time: Traceability is only possible within a certain period of time }\end{array}$ \\
\hline External Controls & $\begin{array}{l}\text { Inspection body } \\
\text { - Availability: Challenge in worldwide availability of accredited/certified IBS } \\
\text { - Gatekeeper: Challenges in ensuring food safety by a gatekeeper in third countries without a QM system in } \\
\text { place } \\
\text { Authorities } \\
\text { - Differences in management of food/feed safety risks within a country, type of control, in control frequency } \\
\quad \text { and in control costs }\end{array}$ \\
\hline \multicolumn{2}{|r|}{ Human Factor } \\
\hline & $\begin{array}{l}\text { - Mentality: Work morale of actors directly (buyer, logistics company) and indirectly (control authorities) } \\
\text { involved } \\
\text { - Behaviour: Diligent behaviour by actors directly (logistics company) or indirectly (e.g. inspectors/control } \\
\text { authorities) involved } \\
\text { - Expertise: Technical knowledge of actors directly (logistics company) and indirectly (control authorities) } \\
\text { involved. } \\
\text { - Awareness of the relevance of logistics processes in the context of food safety of actors directly (logistics } \\
\text { company) and indirectly (control authorities) involved } \\
\text { - Integrity: Non-transparent behaviour of logistics companies, usually economically motivated } \\
\text { - Lack of experience: Needed for a careful implementation of the high quality/safety requirements in the } \\
\text { logistics sector }\end{array}$ \\
\hline \multicolumn{2}{|r|}{ Disruptions and shifts } \\
\hline & $\begin{array}{l}\text { - Shifts in commodity flows, i.e. change in the country of origin are associated with new risks and require a high } \\
\text { degree of flexibility and adaptability of the actors involved } \\
\text { - Disruptions in global commodity flows can lead to uncertainties among the actors involved and time delays or } \\
\text { break of chains (e.g. port congestions) }\end{array}$ \\
\hline \multicolumn{2}{|r|}{ Logistics related conditions } \\
\hline $\begin{array}{l}\text { Infrastructure and } \\
\text { equipment }\end{array}$ & $\begin{array}{l}\text { - Varying type and quality level of infrastructure (e.g. port infrastructure, means of transport, facilities) } \\
\text { depending on factors such as maintenance and resources } \\
\text { Varying availability of infrastructure (e.g. means of transport, roads (esp. in third Countries), storage } \\
\text { facilities) }\end{array}$ \\
\hline Rules and regulations & $\begin{array}{l}\text { - Lack of harmonization in food safety regulations (e.g. Maximum limits for contaminants (ML) or GMOs) } \\
\text { - Impracticability: Difficult implementation of food safety requirements (e.g. in the field of new ML, masked } \\
\text { mycotoxins) } \\
\text { - Imprecision/gaps: Inaccuracies (e.g. type of sanitation) and/or lack of consideration of logistics in EU food } \\
\text { safety laws/regulations } \\
\text { - Lack of food safety regulations: In certain regions of the world, resulting in a lack of controls, also in trade } \\
\text { and logistics }\end{array}$ \\
\hline Weather & $\begin{array}{l}\text { - Rainy conditions: During logistical processes (storage, up-/unloading, transportation) in connection with } \\
\text { poor infrastructure and / or maintenance } \\
\text { - } \quad \text { Climate change: Leads to shifts in production regions and consequently to shifts in global commodity flows } \\
\text { - Weather conditions: Influence product temperature during loading }\end{array}$ \\
\hline Standards & $\begin{array}{l}\text { Diversity and amount: Diversity of quality/safety standards and amount of additional standards (e.g. } \\
\text { - Imstainability) } \\
\text { Imprecision/gaps: Inaccuracies (e.g. sanitation) and/or lack of consideration of important aspects of } \\
\text { logistics, e.g. logistics activities in export countries } \\
\text { - Lack of effectiveness/reliability: Food safety standards do not cover / influence day-to-day business, e.g. } \\
\text { way of working }\end{array}$ \\
\hline Market conditions & $\begin{array}{l}\text { - Market fluctuations: Depending on regional harvest conditions (quality/quantity); can affect the course of } \\
\text { commodity flows and the behaviour of logistics companies (e.g. less attention to food safety due to stress } \\
\text { situation) and trader (e.g. choice of logistics companies) } \\
\text { Consumer trends: Divergent /dynamic trends (veganism / sustainability vs. increase in world population } \\
\text { and meat demand) lead to uncertainties and disruptions }\end{array}$ \\
\hline (New) Technologies & $\begin{array}{l}\text { - } \quad \text { Block chain: Low use of Block chain to improve traceability or information flow through faster processing of } \\
\text { - } \quad \text { Samplata" } \\
\text { - } \quad \text { Monitoring: Low use of sampling innovations (e.g. near-infrared, real-time) } \\
\text { sensors) }\end{array}$ \\
\hline Sociocultural conditions & $\begin{array}{l}\text { - Cultural differences in mentality between countries affect the behaviour of the (logistics) actors involved } \\
\text { (e.g. diligent handling of port infrastructure) } \\
\text { - Education: Differences in the education of logistics companies between countries due to different training } \\
\text { landscape; lower education level in logistics compared to other sectors }\end{array}$ \\
\hline
\end{tabular}




\begin{tabular}{|c|c|}
\hline \multirow[t]{2}{*}{$\begin{array}{c}\text { Sub areas of Critical } \\
\text { Dimension }\end{array}$} & Critical Factor \\
\hline & $\begin{array}{l}\text { - Language: Lack of language skills of the logistics companies (e.g. truck driver) can lead to problems in } \\
\text { complying with national regulations }\end{array}$ \\
\hline Political conditions & $\begin{array}{l}\text { - Political climate: Political instability, new policies (e.g. new president), BREXIT can lead to shifts in trade } \\
\text { and logistics sector (e.g. export tariffs/restrictions) } \\
\text { - Trade war: Conflicts between trading partners on market price developments resulting in shifts of } \\
\text { commodity flows and changes in logistical demand/availability }\end{array}$ \\
\hline \multicolumn{2}{|r|}{ Cooperation } \\
\hline & $\begin{array}{l}\text { - Information flows: Challenge in transparent communication and data interchange in terms of food safety, } \\
\text { such as variation of analytical results; logistical and organisational challenge in the transfer of analytical } \\
\text { certificate and ownership } \\
\text { - Confidence: Long term relationships between supplier and buyer result in more confidence and less control } \\
\text { Role of the buyer } \\
\text { - Power balance in favour of the buyer gives him great influence: e.g. quality / safety specification, conditions } \\
\text { of logistical processes, storage time, redirection of commodity flows and logistics options (ports, logistics } \\
\text { company) } \\
\text { - Responsibility for food quality/safety and corresponding measures: e.g. sampling (plan), handling of } \\
\text { contaminated products, risk assessment (supplier/origin evaluation), and controls/audits: e.g. acceptance } \\
\text { check by feed industry. } \\
\text { Role of the Logistics Company } \\
\text { - Responsibility for maintenance of agreed storage and transportation conditions through control measures } \\
\text { (e.g. sanitation, preload) in the scope of QM } \\
\text { - No food safety control / decision: Responsibility in terms of food safety is limited to visual checks. No } \\
\text { power concerning decision taking in challenging conditions during logistical processes (e.g. discharging by } \\
\text { rain) } \\
\text { - Lack of knowledge: Little or no knowledge about the conditions of the goods in the exporting country } \\
\text { (quality, handling, storage) }\end{array}$ \\
\hline \multicolumn{2}{|r|}{ Main Characteristics of the procurement sector } \\
\hline & $\begin{array}{l}\text { - Chain fragmentation: Complexity and lack of transparency due to a large number of actors, not all certified } \\
\text { and due to different practices } \\
\text { - Negative image: Low attractiveness of the logistics sector due to difficult working conditions resulting in } \\
\text { high labour turnover, lack of junior staff, low education level } \\
\text { - Competitive pressure: Choosing the safest option in terms of logistics often means no longer being } \\
\text { competitive on the market as trader / feed industry } \\
\text { - Low margins in the procurement/trading of agricultural raw materials conflict with costly food safety } \\
\text { requirements } \\
\text { - Lack of economic incentive for logistics companies to invest more in the quality and safety of logistics } \\
\text { processes } \\
\text { Economic pressure: Cost reduction/effectivity is necessary for survival in the logistics sector; saving money } \\
\text { is more important than quality/safety assurance }\end{array}$ \\
\hline \multicolumn{2}{|r|}{ Port characteristics } \\
\hline & 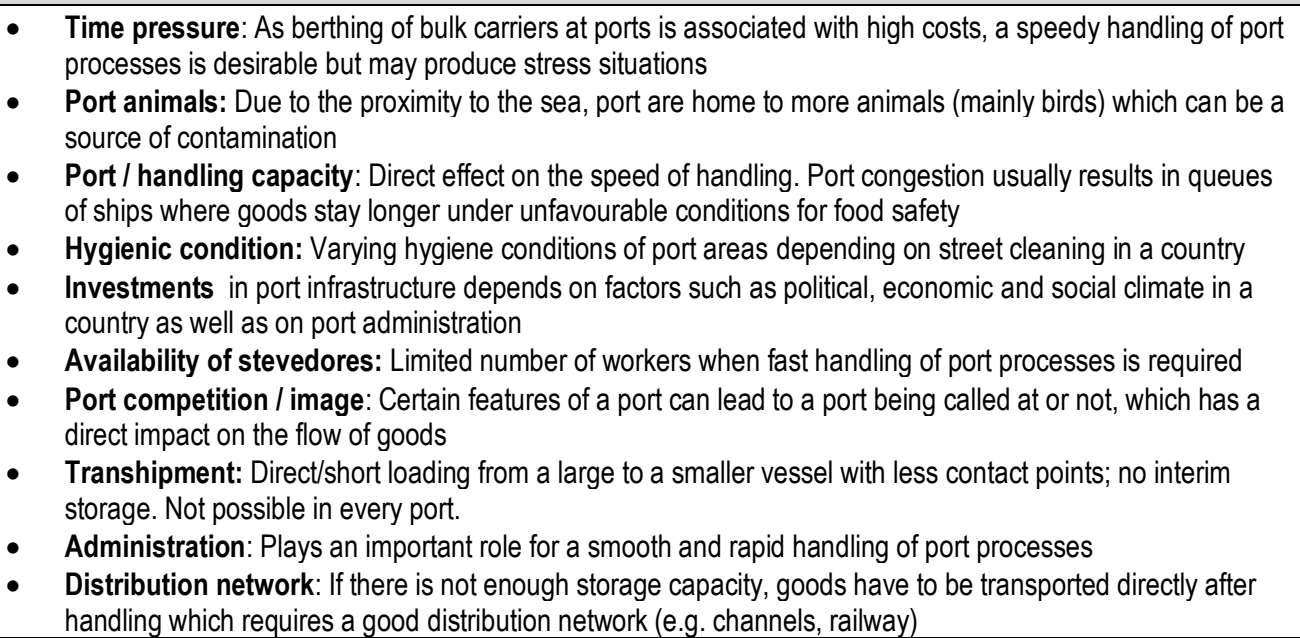 \\
\hline
\end{tabular}

Milena Zupaniec has been working as a research assistant at the German Federal Institute for Risk Assessment in the Department Safety in the Food Chain before she started a dissertation on the impact of logistics on food safety in cooperation with the Humboldt-University of Berlin. Her generic focus of research is centred around risk identification related to food and feed safety in global commodity flows and agricultural trade. 
Dr Helmut Schafft is senior staff scientist at the German Federal Institute for Risk Assessment (BfR) in Berlin. He is an expert in risk assessment in feed and food. His focus includes methodology for consumer health risk assessment, including approaches to weight of toxicological evidence for human hazard and cross-species extrapolation. Dr. Schafft received a PhD in Animal Sciences from University of Goettingen and a Dr. habil. (Habilitation) from Humboldt-University of Berlin.

Dr Ann-Kathrin Lindemann was a research assistant at the Institute of Communication Science at the University of Hohenheim from 2011 to 2017. In 2018, she joined the German Federal Institute for Risk Assessment. She works as a Senior Scientific Officer in the Unit Crisis Prevention and Coordination within the Department Risk Communication. Her research focuses on risk perception, risk and crisis communication and the development and evaluation of different risk communication formats.

Dr Robert Pieper has been working in the field of animal nutrition and feedstuff evaluation for more than 15 years in Germany and Canada. Since 2018, he is head of the group Feed and Feed Additives in the Department Safety in the Food Chain at the German Federal Institute for Risk Assessment. His focus are all safety issues related to the transfer of (regulated and yet not regulated) undesirable substances and microbial hazards from animal feed into food of animal origin. He has published more than 100 papers in peer-reviewed journals.

Dr Anneluise Mader is coordinating the Department Safety in the Food Chain at the German Federal Institute for Risk Assessment. Special focus in research has been aligned on feed, wild and farm animal and food production, microbial and chemical food safety issues as well as consumer protection and risk assessment aspects. She has published more than 30 publications in peer-reviewed journals dealing with various topics from farm to fork. 